\title{
Effect of Thymic Humoral Factor on Cellular Immune Functions of Normal Children and of Pediatric Patients with Ataxia Telangiectasia and Down's Syndrome
}

\author{
Z. T. HANDZEL, Z. DOLFIN, S. LEVIN, Y. ALTMAN, T. HAHN, N. TRAININ, AND N. GADOT \\ John Askin Pediatric Research Laboratory, Kaplan Memorial Hospital, Rehovot; Department of Cell Biology, The \\ Weizmann Institute of Science, Rehovot, and Soroka Medical Center, Beer-Sheva, Israel
}

\section{Summary}

Cellular immune functions of nine Down's syndrome patients and of nine with Ataxia telangiectasia vs. nine normal children and nine cord bloods, were evaluated using in vitro assays of peripheral blood lymphocytes.

The in vitro assays included $\mathrm{E}$ rosette formation, antilymphocytic cytotoxicity by an antithymic antiserum and leukocyte migration inhibition factor (LIF) production. The mitogens and antigens used were phytohemagglutinin, purified protein derivative, and monilia antigen. The effect of a thymic hormone (THF) on these parameters was evaluated and it was administered therapeutically to three Down's syndrome patients and to two patients with Ataxia telangiectasia. Most deficient T-cell functions were reversed to normal after incubation of the lymphocytes with THF, or after THF therapeutic administration. In two Down's syndrome cases, the clinical course was not altered by THF administration, while one seemed to benefit from it markedly. One of the Atactic patients recovered from a severe viral infection, while the other died from intractable bronchopneumonia.

\section{Speculation}

It has been extensively demonstrated that THF has the capacity of inducing differentiation and maturation of lymphocytes of T-cell lineage. It is suggested that THF has also the capacity of reversing the impairment of $\mathrm{T}$-cell functions associated with genetically determined diseases, such as Ataxia telangiectasia and Down's syndrome.

Accumulating body of evidence indicates that THF stimulates cellular immune functions in vitro and in vivo, through a specific activation of early T-lymphocytes (30). Moreover it has been demonstrated that THF isolated in our laboratory (15), partially reconstitutes the immunologic damage caused by the removal of the thymus (26). Recently, the possibilities of the therapeutic potential of THF in humans have been reported $(31-33,36)$. From this limited clinical experience, it could be learned that THF administration led to reconstitution of $T$-cell function, which was sometimes reflected in a substantial clinical improvement. Furthermore, THF treatment was not accompanied by significant side effects.

We have investigated two genetic disorders associated with various cellular immune defects: Ataxia telangiectasia (AT) (18, 21 ) and Down's syndrome (DS) (17). In both, T-cell numbers and functions in peripheral blood lymphocytes (PBL) are frequently diminished $(17,21)$. Therefore, we considered these syndromes to be suitable models for evaluation of the effect of THF on T-cell functions in vitro and in vivo. Encouraging preliminary results (8) have prompted the present investigation.

MATERIALS AND METHODS

\section{PATIENTS}

Informed consent was obtained from parents of all patients receiving THF treatment, after the purpose of its administration had been explained to them.

(1) Blood samples from nine normal children, in general good health, hospitalized for elective surgery or for observation after minor traumata, in the range of 2-12 yr, were used as controls. The blood samples were drawn at the time of routine biochemical investigations (before operations in the surgical patients). In addition, nine cord blood samples from normal newborns were assayed.

(2) Nine patients with AT, belonging to four sibships, aged 4 $12 \mathrm{yr}$, in various stages of psychomotor incapacitation were investigated. Only patients 8 and 9 suffered from life-threatening infections at the time of blood sampling and were treated with THF.

Patient 8, a 10-yr-old boy, had a severe progressive bronchopulmonary infection resistant to antibiotic treatment. THF was administered at a relatively advanced stage of his disease, by intramuscular injections of $1 \mathrm{mg}$ protein $/ \mathrm{kg} /$ day during 4 weeks.

Patient 9, a 71/2-yr-old boy, usually not suffering from a special tendency to infections, acquired a rapidly progressive varicella complicated by pneumonitis, becoming critically ill within 2 days. He was treated by the same schedule of THF as patient 8 , but for 5 days only.

(3) Nine patients with DS, including three newborn infants, the oldest being 6-yr-old. THF was administered intramuscularly to three patients, two of them newborns, $1 \mathrm{mg}$ protein $/ \mathrm{kg} /$ day in two doses; in the first for 20 days, in the second for 8 days, and then once a week for 3 weeks. Two patients suffered from intractable diarrhea, bronchopneumonia, candidiasis, and bouts of sepsis. To the third patient, THF was given for 3 weeks, $1 \mathrm{mg}$ protein $/ \mathrm{kg} /$ day and then $0.5 \mathrm{mg} / \mathrm{kg} /$ day for 1 week. She was a 2 -yr-old girl with congenital heart disease, persistent pyrexia, and progressive bronchopneumonia, causing increasing dyspnoea and anoxia.

\section{SEPARATION OF LYMPHOCYTES}

Ten ml blood was drawn into sterile, heparinized tubes and the lymphocytes were separated on Ficoll-isopaque (LymphoprepNyegard \& Co., Oslo) gradients, as described by Bøyum (6). 


\section{T-CELL PERCENT OF PBL}

This was assayed by spontaneous $\mathrm{E}$ rosette formation with sheep red blood cells (34) and by a microcytotoxicity test, using a goat antihuman thymus antiserum with rabbit serum as a source of complement (17). Briefly, $10^{9}$ human fetal thymocytes were injected iv into goats, with two subsequent boosters at biweekly intervals and a third one in the form of intradermal injections of thymocytes emulsified in complete Freund's adjuvant. The procedure was performed by Dr. Z. Eshhar, The Weizmann Institute of Science, Rehovot. The antiserum raised was adsorbed on human $\mathrm{AB} \mathrm{Rh}+$ erythrocytes, thrombocytes, fetal liver tissue, and chronic lymphatic leukemia lymphocytes. The $\gamma$-globulin fraction was precipitated with ammonium sulfate. Cell death was assessed by trypan blue exclusion.

LIF

LIF production was assayed by incorporating $1 \cdot 10^{6}$ lymphocytes and $3 \cdot 10^{6}$ polymorphonuclear granulocytes in a $20 \lambda$ agarose droplet with M199 medium on a $5 \mathrm{~cm}$ Petri dish (13). The linear migration of cells out of the droplet in response to phytohemagglutinin (PHA) (Wellcome-Burroughs, England) and to purified protein derivative (PPD) (Connaught Laboratories, Willowdale, Canada) was measured after $18 \mathrm{hr}$ incubation in $37^{\circ} \mathrm{C}$ and $5 \%$ $\mathrm{CO}_{2}$, using a micrometric lens in an inverted microscope (10). The percent of migration inhibition was calculated as follows:

$$
\left(1-\frac{\text { migration with antigen }}{\text { migration of control }}\right) \times 100
$$

\section{RESPONSE TO MITOGENS}

Response to PHA and Concanavalin A (Miles-Yeda, Rehovot, Israel) was determined as described by Rotter et al. (23). One mg PHA or $3 \mathrm{mg}$ Concanavalin A were added to each culture tube (2058 Falcon Plastics, CA) containing $0.5 \cdot 10^{6}$ lymphocytes and incubated for 3 days at $37^{\circ} \mathrm{C}$ in $5 \% \mathrm{CO}_{2}-95 \%$ air. Two hr before the end of the incubation period, a pulse of $2.5 \mu \mathrm{Ci}$ of tritiated thymidine (Negev, Israel) was added to each tube and shaken at $37^{\circ} \mathrm{C}$. Cultures were interrupted by placing on ice at $4^{\circ} \mathrm{C}$. The content of each culture tube was poured onto a fiberglass filter (Tamar, Jerusalem, Israel) in a filtering cell harvester (Yeda, Rehovot, Israel) and the uptake of ${ }^{3} \mathrm{H}$-thymidine was determined in a Tricarb (Packard) $\beta$ scintillation counter. A stimulation index was calculated by dividing the counts of mitogen stimulated cultures by the nonstimulated response of the same patient.

\section{THF}

Extracts of calf thymuses were prepared and dialyzed as previously described (16). The preparations which were thus partially purified, were adjusted to a standard concentration of $1 \mathrm{mg}$ protein $/ \mathrm{ml}$. It has been established that the active principle of THF is a polypeptide of molecular weight ca. 3000 (16). Each batch of lymphocytes was divided into two, one sample being incubated for $60 \mathrm{~min}$ with $13-40 \mu \mathrm{g} / \mathrm{ml} \mathrm{THF}$, and the other without. Then, the assays described previously were performed on both.

\section{NORMAL VALUES IN OUR LABORATORY}

E rosette percent range within $50-70 \%$. Changes of $10 \%$ or more are considered significant.

LIF, $20 \%$ migration inhibition or more. Changes of $12 \%$ or more are considered significant.

$E$ rosette and LIF levels are based on experience in assaying 350 clinical cases.

\section{RESULTS}

No significant difference was found in PBL T-cell percent and LIF production in normal children and random cord blood samples. THF had no enhancing effect on these parameters (Table 1), and even a trend to decrease the normal values was noted.

PBL from AT patients showed a heterogeneous in vitro immune response (Table 2 ). In five of seven patients, the $E$ rosetting cell percent was within normal range, THF having either no effect or even depressing it. In the remaining two cases, $\mathrm{E}$ rosettes were diminished and they were elevated after incubation with THF (43-52\% in case 2 , and $42-62 \%$ in case 4 ). According to LIF production, the patients could be divided into two groups. The first four cases showed a normal migration inhibition response both to PHA and to PPD, THF not being able to improve it, except for the PHA response in case 4 , which was $33 \%$ and somewhat enhanced by THF (to $45 \%$ ). The other three patients demonstrated a markedly depressed LIF response which was much improved by THF. Only in case 7 was there no response to PPD after incubation with THF. In Table 3, the results of in vitro immune functions of patients 8 and 9 , before and after THF treatment, are shown.

The clinical course in patient 8 remained unchanged, despite THF administration, and he expired 2 weeks later, due to respiratory insufficiency. In patient 9 , however, a dramatic improvement occurred after 3 days of THF therapy, consisting in rapid regression of the pulmonary lesions and arrest of the dissemination of the vesicular rash. After 5 days, he was afebrile, all vesicopustular lesions had dried out, and THF was discontinued. The clinical course in this patient was reminiscent of that recently described by Zaizov et al. (36) in children with lymphoproliferative disorders and generalized varicella.

Table 2. In vitro effect of THF on AT T-cell parameters

\begin{tabular}{ccccccccc}
\hline & \multicolumn{2}{c}{ E Rosettes $^{1}$} & & \multicolumn{2}{c}{ LIF $^{3}$-PHA } & & \multicolumn{2}{c}{ LIF-PPD } \\
\cline { 2 - 3 } \cline { 7 - 8 } Case & Spont. $^{2}$ & THF & & Spont. & THF & & Spont. & THF \\
\hline 1 & 70 & 63 & & 44 & 26 & & 53 & 54 \\
2 & 43 & 52 & & 50 & 49 & & 47 & 41 \\
3 & 51 & 39 & & 50 & 46 & & 45 & 45 \\
4 & 42 & 62 & & 33 & 45 & & 30 & 31 \\
5 & 59 & 46 & & 3 & 32 & & 12 & 33 \\
6 & 64 & 70 & & 10 & 32 & & 0 & 22 \\
7 & 60 & 61 & & 0 & 16 & & 0 \\
\hline
\end{tabular}

' Percent of PBL.

${ }^{2}$ Spont. = spontaneous.

${ }^{3}$ Percent inhibition of linear leucocytic migration.

Table 1. Effect of THF on T-cell parameters of lymphocytes of normal infants and children ${ }^{1}$

\begin{tabular}{|c|c|c|c|c|c|c|c|}
\hline \multirow[b]{2}{*}{ Patients } & \multirow[b]{2}{*}{$N$} & \multicolumn{2}{|c|}{ E Rosettes $^{2}$} & \multicolumn{2}{|c|}{ LIF $^{4}-\mathrm{PHA}^{5}$} & \multicolumn{2}{|c|}{ LIF $^{4}-\mathrm{PPD}$} \\
\hline & & Spont. $^{3}$ & THF & Spont. & THF & Spont. $^{3}$ & THF \\
\hline $\begin{array}{l}\text { Normal children } \\
\text { Normal newborns }\end{array}$ & $\begin{array}{l}9 \\
9\end{array}$ & $\begin{array}{l}60 \pm 7 \\
55 \pm 13\end{array}$ & $\begin{array}{l}64 \pm 6 \\
49 \pm 12\end{array}$ & $\begin{array}{l}40 \pm 9 \\
40 \pm 6\end{array}$ & $\begin{array}{l}33 \pm 7 \\
35 \pm 7\end{array}$ & $\begin{array}{c}35 \pm 11 \\
0 \pm 2\end{array}$ & $\begin{array}{l}18 \pm 6 \\
16 \pm 9\end{array}$ \\
\hline
\end{tabular}

\footnotetext{
'All values expressed as Mean $\pm \mathrm{SD}$.

${ }^{2}$ Percent of PBL.

${ }^{3}$ Spont. $=$ Spontaneous.

${ }^{4}$ Measured by percent inhibition of linear leucocytic migration.

${ }^{5} \mathrm{LIF}$ production in response to $\mathrm{PHA}$.
} 
Table 3. Effect of THF treatment on immune functions of Ataxia telangiectasia

\begin{tabular}{|c|c|c|c|c|c|c|}
\hline \multirow[b]{2}{*}{ Case } & & \multirow{2}{*}{$\begin{array}{c}\text { E } \\
\text { Rosettes }\end{array}$} & \multicolumn{2}{|c|}{ LIF } & \multicolumn{2}{|c|}{${ }^{3} \mathrm{H}-\mathrm{Td}$ Uptake' } \\
\hline & & & PHA & Con $\mathrm{A}$ & PHA & Con $\mathrm{A}$ \\
\hline \multirow{3}{*}{8} & Spontaneous & 40 & 35 & 22 & 9 & 18 \\
\hline & $\mathrm{THF}$ in vitro & 58 & 28 & & 21 & 32 \\
\hline & THF treatment & 50 & 46. & 32 & & \\
\hline \multirow{4}{*}{9} & Spontaneous & 39 & 12 & & & \\
\hline & THF in vitro & 44 & 15 & & & \\
\hline & THF treatment ( 2 days) & 43 & 24 & & & \\
\hline & After 8 months & 45 & 24 & 17 & 3.6 & 1.5 \\
\hline
\end{tabular}

${ }^{1}$ Stimulation indices.

Table 4. In vitro effect of THF on T-cell parameters in Down's syndrome

\begin{tabular}{|c|c|c|c|c|c|c|c|c|}
\hline \multirow[b]{2}{*}{ Case } & \multicolumn{2}{|c|}{ E-rosettes ${ }^{1}$} & \multicolumn{2}{|c|}{ ATS-CTX ${ }^{1,3}$} & \multicolumn{2}{|c|}{ LIF $^{4}-$ PHA } & \multicolumn{2}{|c|}{ LIF-PPD } \\
\hline & Spont. $^{2}$ & THF & Spont. & THF & Spont. & THF & Spont. & THF \\
\hline 1 & 28 & 35 & 40 & 44 & 0 & 41 & 7 & 22 \\
\hline 2 & 48 & 72 & 30 & 55 & 0 & 29 & & \\
\hline 3 & 41 & 52 & 43 & 42 & & & & \\
\hline 4 & 38 & 44 & & & 16 & 20 & 24 & 40 \\
\hline 5 & 45 & 69 & & & 0 & 20 & 0 & 13 \\
\hline 6 & 30 & 33 & & & 0 & 13 & & \\
\hline
\end{tabular}

' Percent of PBL.

${ }^{2}$ Spont. $=$ Spontaneous.

${ }^{3}$ ATS-CTX = Antithymocytic serum cytotoxicity.

${ }^{4}$ Percent inhibition of linear leucotytic migration.

Table 5. In vivo effect of THF in Down's syndrome $e^{1}$

\begin{tabular}{|c|c|c|c|c|c|}
\hline \multirow[b]{2}{*}{ Case } & & \multirow{2}{*}{$\begin{array}{c}\mathrm{E} \\
\text { Rosettes }\end{array}$} & \multirow{2}{*}{$\begin{array}{l}\text { ATS- } \\
\text { CTX }\end{array}$} & \multicolumn{2}{|c|}{ LIF } \\
\hline & & & & PHA & PPD \\
\hline \multirow{2}{*}{7} & Spontaneous & 22 & 15 & 0 & 0 \\
\hline & THF treatment & 47 & 30 & 6 & 46 \\
\hline \multirow{3}{*}{8} & Spontaneous & 40 & 32 & 8 & \\
\hline & THF in vitro & 49 & & 27 & \\
\hline & THF treatment & 53 & & 40 & 17 \\
\hline \multirow{3}{*}{9} & Spontaneous & 53 & & 25 & 6 \\
\hline & THF in vitro & 67 & & 32 & 36 \\
\hline & THF treatmant & 76 & & 50 & 9 \\
\hline
\end{tabular}

${ }^{1}$ Abbreviations and units as in Table 3.

Table 4 summarizes the in vitro effect of THF on lymphocytes of six DS patients. In all patients, E rosettes were decreased as compared to the normals (Table 1) and LIF production was markedly diminished. In three patients, E rosetting capacity was markedly augmented, while in two more, a slight increase occurred. LIF production was strikingly increased in response to PHA in three of five patients. The response to PPD was also improved in three of three cases.

Patients 7-9 were treated with THF. In all three (Table 5), a reconstitution of in vitro cellular immune functions occurred, after 2 weeks of therapy, although it varied in quantity and quality from case to case and from assay to assay. Thus, in case 7, E rosette formation was doubled (from 22 to 47\%), LIF-PPD response was markedly enhanced (from 0 to $46 \%$ inhibition), but LIF-PHA was not affected. In case 9, although LIF-PPD was significantly restored by THF in vitro, it did not change after THF therapy. All the three Down's syndrome patients treated with THF were seriously ill when treatment was begun, suffering from severe bronchopulmonary and gastrointestinal infections. The clinical course of the first two was not altered by the treatment and they both died within a few weeks.
The third patient was a 2-yr-old, suffering from congenital heart disease and severe, protracted pulmonary infections. During the treatment, her pneumonia cleared completely for the first time and her general condition improved remarkably.

No toxic or allergic effects whatsoever were observed in any of the five patients treated with THF.

\section{DISCUSSION}

Thymic hormones are supposed to act on partial cellular immune defects, in which a substrate of T-precursors still exists (1, $20,34)$. A variety of factors of thymic origin has been isolated ( 9 , $25,26)$ and found to enhance maturation of such precursors $(1,3$, $19,20,26,32,34$ ).

Studies in our laboratory have determined that the biologic effects of THF, a peptide hormone isolated from calf thymuses, are specific to the thymus because they cannot be reproduced by tissues such as muscle, liver, kidney, spleen, and lymph nodes (2830). Moreover, no toxic effects of THF have been noticed after parenteral administration.

Thymic factors have been shown to increase impaired numbers of $\mathrm{E}$ rosettes $(2,34)$ in $\mathrm{PBL}$ and to improve other in vitro cellularimmune functions in humans $(1,36)$. THF modifies in particular E rosette formation, $\operatorname{LIF}$ production $(8,11,12)$ and graft-vs.-host reactions $(31,33)$ in human $\mathrm{PBL}$. In the light of the above, DS and AT were considered suitable for clinical trials with THF. In almost all cases of DS, a partial T-cell deficiency is demonstrable, expressed by a reduced percent of $\mathrm{T}$-cells in blood, in vitro impaired T-cell function, and lack of dermal delayed hypersensitivity reactions to some antigens $(5,7,14,17,22,24)$. It could be seen that the effect of THF on DS lymphocytes was fairly constant, causing enhancement of $E$ rosette formation and improvement of in vitro and in vivo $\mathrm{T}$-dependent functions in most patients, to near normal levels. Regarding AT, a less constant effect of THF was observed, though reconstitution of $\mathrm{T}$-dependent functions was more prominent in those patients with obvious $\mathrm{T}$-cell defects. Similar results on an AT patient have recently been reported (4).

From the present observations, it was concluded that the reconstitution effect of THF is most prominent when T-functions are depressed and that no enhancing effect is achieved in patients with normal cellular immune functions; occasionally a significant decrease in the expression of $\mathrm{T}$-cell parameters could be noted (Table 2, patient 1).

An important question is whether THF can alter the clinical course of severe, recurrent infections in patients with $\mathrm{T}$-dependent deficiencies. The three DS cases treated with THF do not resolve this problem yet. The first two, patients 7 and 8 , were very small and critically ill babies who did not benefit from the treatment. However, it is possible that when THF was instituted they had already reached an irreversible state of secondary metabolic disturbances. This interpretation is supported by the laboratory findings in patient 7 , demonstrating an almost complete lack of T-cell activity. However, the third case, (patient 9) improved dramatically shortly after starting the treatment and remained free from serious infections for many weeks. Yet, a direct cause and effect relationship could not be established. One of the AT pa- 
tients, suffering from severe varicella, showed a rapid and remarkable recovery, while the second, with a bronchopulmonary infection, remained unaffected by THF. Thus, two out of five patients derived a demonstrable clinical benefit from the treatment. None of the treated patients showed any side effect as a consequence of THF administration.

This report should be regarded as preliminary. The authors are aware that there are not enough intergroup variables to enable a mathematical analysis of the data. Therefore, the evaluation of the patients' clinical course is descriptive only. However, if this experience is added to that obtained with THF by others $(31-33$, 36 ), the overall results encourage a further and wider investigation of the possible therapeutic value of THF in various T-dependent cellular immune defects. For this purpose, a controlled clinical trial is currently planned.

\section{REFERENCES AND NOTES}

1. Auiti, F., Schirrmacher, V., Ammirati, P., and Fiorilli, M.: Effect of thymus factor on human precursor T lymphocytes. Clin. Exp. Immunol., 20: 499 (1975).

2. Bach, M. A. and Bach, J. F.: Studies on thymus products. VI. The effects of cyclic nucleotides and prostaglandins on rosette forming cells. Interactions with thymic factor. Eur. J. Immunol., 3: 778 (1973).

3. Bach, J. F. and Dardenne, M.: Studies on thymus products. II. Demonstration and characterization of a circulating thymic hormone. Immunol., 25: 353 (1973).

4. Boumsell, L., Incefy, G. S., Bernard, A., Schwartz, S., Smithwick, E., and Good, P. A.: T-lymphocyte differentiation in vitro in Ataxia Telangiectasia associated with lymphosarcoma. J. Pediatr., 87: 435 (1975).

5. Boxer, L. A. and Yokoyama, M.: Lymphocyte antigens in patients with Down's syndrome. Vox Sang., 22: 539 (1972).

6. Bøyum, A.: Ficoll-Hypaque method for separating mononuclear cells and granulocytes from human blood. Scand. J. Clin. Lab. Invest., 21: 97, (Suppl.) (1968).

7. Burgio, G. R., Ugazio, A. G., and Nespoli, L.: Peripheral blood "Rosette-forming lymphocytes" in Down's syndrome. Experientia, 30: 818 (1974).

8. Dolfin, Z., Handzel, Z. T., Altman, Y., Hahn, T., Levin, S., and Trainin, N.: In vitro effect of Thymic Humoral Factor on human peripheral blood lymphocytes from normal and immunodeficient patients. 8th Annual Meeting of the Israel Immunological Society, Tel-Aviv, Israel, Isr. J. Med. Sci., 12: 1259 (1976).

9. Goldstein, A. L., Guha, A., Zatz, M. M., Hardy, M. A., and White, A.: Purification and biological activity of thymosin, a hormone of the thymus gland. Proc. Natl. Acad. Sci., 69: 1800 (1972).

10. Hahn, T., Levin, S., and Handzel, Z. T.: Leucocyte migration inhibition factor (LIF) production by lymphocytes of normal children, newborns and children with immune deficiency. Clin. Exp. Immunol. 24: 448 (1976).

11. Handzel, Z. T., Levin, S., Ashkenazi, A., Hahn, T., Altman, Y., Czernobilsky, B., Schechter, B., and Trainin, N.: Immune deficiency of T-system with possible T-cell regulatory activity defect. Isr. J. Med. Sci., 13: 347 (1977).

12. Handzel, Z. T., Levin, S., Hahn, T., Altman, Y., Ashkenazi, A., Trainin, N., and Shechter, B.: Infantile partial thymic deficiency: correction of some in vitro $\mathrm{T}$ functions by THF. 7th Annual Meeting of the Israel Immunological Society, Jerusalem, Israel, Isr. J. Med. Sci., 11: 1391 (1975).

13. Harrington, J. T. and Stastny, P.: Macrophage migration from an agarose droplet: development of a micro-method for assay of delayed hypersensitivity. J. Immunol., 110: 752 (1973).

14. Hsia, D. Y., Justice, P., Smith, G. F., and Dowben, R. M. Down's syndrome. A critical review of the biochemical and immunological data. Am. J. Dis. Child. 121: 153 (1971).

15. Kook, A. I. and Trainin, N.: Hormone-like activity of a thymus humoral factor on the induction of immune competence in lymphocytes. J. Exp. Med. 139:
193 (1974)

16. Kook, A. I., Yakir, Y., and Trainin, N.: Isolation and partial chemical characterization of THF, a thymus hormone involved in immune maturation of lymphoid cells. Cell. Immunol., 19: 151 (1975).

17. Levin, S., Nir, E., and Mogilner, B. M.: T-system deficiency in Down's syndrome. Pediatrics, 56: 123 (1975).

18. Levin, S. and Perlov, S.: Ataxia Telangiectasia in Israel. Isr. J. Med. Sci., 7: 1535 (1971).

19. Lonai, P., Mogilner, B., Rotter, V., and Trainin, N.: Studies on the effect of a thymic humoral factor on differentiation of thymus-derived lymphocytes. Eur. J. Immunol. 3: 21 (1973).

20. Marx, J. L.: Thymic hormones: inducers of T-cell maturation. Science, I87: 1183 (1975).

21. McFarlin, D. E., Strober, W., and Waldman, T. A.: Ataxia telangiectasia. Medicine, 5I: 281 (1972).

22. Mellman, W. J., Younkin, L. H., and Baker, D.: Abnormal lymphocyte function in trisomy 21. Ann. N. Y. Acad. Sci., 171: 537 (1970).

23. Rotter, V., Schlesinger, M., Kalderon, R., and Trainin, N.: Response of human lymphocytes to PHA and Con A, dependent on and regulated by THF, a thymic hormone. J. Immunol., 117: 1927 (1976).

24. Szigeti, R., Revesz, T., and Schuler, D.: Cell mediated immune response in patients with Down's syndrome. Acta Paediatr. Acad. Sci. Hung., 15: 31 (1974).

25. Touraine, J. L., Touraine, F., Dutruge, J., Gilly, J., Colon, S., and Gilly, R.: Immunodeficiency diseases. I. T-lymphocyte precursors and T-lymphocyte differentiation in partial Di-George syndrome. Clin. Exp. Immunol., 21: 39 (1975).

26. Trainin, N.: Thymic hormones and the immune response. Physiol. Rev., 54: 272 (1974).

27. Trainin, N., Bejerano, A., Strahilevitch, M., Goldring, D., and Small, M.: A thymic factor preventing wasting and influencing lymphopoiesis in mice. Isr. J. Med. Sci., 2: 549 (1966).

28. Trainin, N. Kook, A. I., Umiel, T., and Albala, M.: The nature and mechanism of stimulation of immune responsiveness by thymus extracts. Ann. N. Y. Acad. Sci., 249: 349 (1975).

29. Trainin, N. and Linker-Israeli, M.: Restoration of immunologic reactivity. of thymectomized mice by calf thymus extracts. Cancer Res., 27: 309 (1967).

30. Trainin, N., Small, M., Zipori, D., Umiel, T., Kook, A. l., and Rotter, V.: Characteristics of THF, a thymic hormone, In: D. W. van Bekkum: Biological Activity of Thymic Hormones, p. 117-144 (Kooyker Scientific Publishers, Rotterdam, Netherlands), (1975).

31. Varsano, I., Danon, Y., Jaber, L., Livni, E., Shohat, B., Yakir, Y., Shneyour, A., and Trainin, N.: Reconstitution of T-cell function in patients with subacute sclerosing panencephalitis treated with thymus humoral factor. Isr. J. Med. Sci., 12: 1168 (1976).

32. Varsano, I., Danon, Y., Matoth, Y., Shohat, B., Livni, E., Shneyour, A., and Trainin, N.: Use of thymic humoral factor (THF) in a child critically ill with Rheumatoid Arthritis and impaired cellular immunity. 5th Meeting of the European Pediatric Society of Haematology and Immunology, Caesarea, Israel Pediatr. Res. Suppl., 60 (1976)

33. Varsano, I., Schonfeld, M., Matoth, Y., Shohat, B., Englander, T., Rotter, V., and Trainin, N.: Severe disseminated adenovirus infection successfully treated with a thymic humoral factor, THF. Acta Paediatr. Scand., 66: 329 (1977).

34. Wara, D. W., Goldstein, A. L., Doyle, N. E., and Amman, A. J.: Thymosin activity in patients with cellular immunodeficiencies. N. Engl. J. Med., 292: 70 (1975).

35. Wybran, J., Carr, M. C., and Fudenberg, H. H.: The human rosette-forming cell as a marker of a population of thymus-derived cells. J. Clin. Invest., 51: 2537 (1972).

36. Zaizov, R., Vogel, R., Cohen, I., Varsano, I., Shohat, B., Rotter, V., and Trainin, N.: Thymic hormone (THF) therapy in immunosuppressed children with lymphoproliferative neoplasia and generalized varicella. Biomedicine, 27: 105 (1977).

37. This publication is part of work done with a grant No: $17 / 76$ of the Israel Cancer Association.

38. Received for publication May 20, 1977.

39. Accepted for publication July 14,1978 . 